EDITORIAL

\title{
Prehypertension, Patient Outcomes, and the Knowledge Base of Family Medicine
}

\author{
Lee Green, $M D, M P H$ \\ Department of Family Medicine, University of Michigan, Ann Arbor, Mich
}

Ann Fam Med 2005;3:292-293. DOI:10.1370/afm.374.

I $\mathrm{n}$ this issue of the Annals of Family Medicine, Liszka et al present their analysis of long-term followup of the majority of the members of the original NHANES I cohort, examining clinical outcomes against initial blood pressures and cardiovascular risk factor profiles. ${ }^{1}$ They find observational support in terms of patient-oriented outcomes for the 2003 report of the Joint National Commission on Prevention, Detection, and Treatment of High Blood Pressure (JNC 7). ${ }^{2}$ The JNC 7 recommended that we be concerned about patients with prehypertension: systolic pressures between 120 and $139 \mathrm{~mm} \mathrm{Hg}$, or diastolic pressures between 80 and $89 \mathrm{~mm} \mathrm{Hg}$. Even in the lower half of that range, patients with 1 or more risk factors (ie, almost all our patients) suffered increased rates of heart failure, strokes, and coronary disease.

As JNC 7 was developed, we on the panel engaged in vigorous debate about whether and how to include prehypertension in our recommendations. Cross-sectional data clearly associated prehypertension with adverse outcomes, and Framingham longitudinal data showed the high likelihood of progression to hypertension, so we could not ignore the issue. The size of the sample needed convinced us that we could not realistically hope for a prospective randomized trial, so we would have to formulate our recommendation on observational data. Hence, well-done studies from several populations and using varying research methods are essential to assessing the validity of the JNC 7 recommendations. Liszka et al's analysis is technically

Conflict of interest: none reported

\section{CORRESPONDING AUTHOR}

Lee Green, MD, MPH

Department of Family Medicine

University of Michigan

Ann Arbor, MI 48109

greenla@umich.edu exemplary; more importantly, it is clinically representative of the patients we see in daily practice. The external validity of their results is supported further by the similar findings of Russell, Valiyeva, and Carson, ${ }^{3}$ who used different methods (a simulation based on NHANES III cross-sectional data).

These findings challenge us quite directly to think about how we practice. We tend to accept or ignore not-quite-controlled blood pressure more than is good for our patients-even blood pressure that is hypertensive, let alone prehypertensive. ${ }^{2}$ Tierney et $\mathrm{al}^{4}$ showed the outcome-predicting utility of a single elevated office blood pressure reading. Adding to that finding, Liszka et al's clear demonstration of the harm that even prehypertension does to our patients may help reframe our thinking and perhaps encourage us to overcome our clinical inertia ${ }^{5}$ to act appropriately on an abovegoal blood pressure reading at an office visit.

The large role played by the interaction of blood pressure and other risk factors calls for doing what family physicians do best: thinking of the whole patient. For prehypertension, a healthier lifestyle is the treatment. That treatment has benefits across many diseases, and even absent diseases a healthier lifestyle improves wellness, so we have many reasons to work on lifestyle issues with our patients.

How can we work on this effectively? That question takes us beyond our clinical practices, into the policy and research arenas. The most obvious policy issue is that the patient-centered communication and follow-up necessary for working with patients on healthy lifestyles take time, and it remains difficult for us to secure fair compensation for that time. With so much of the illness we treat being the result of unhealthy lifestyle, and with the high and climbing prevalence of prehypertension in our practices, finding ways within our offices, as well as working with payers to make it possible to do what should be done, is essential. The American Academy of Family Physicians 
and its state chapters are best positioned to take up this challenge.

Another policy issue that family physicians will have to consider is joining with others in the community to find out what in the community helps or works against healthy lifestyles. There are pervasive disincentives to healthy exercise and incentives to unhealthy diet built into the very structure of our cities and towns and our economy. When we prescribe drugs, we know (usually) that our patients can fill the prescription. What about when we prescribe healthy lifestyle? We can help our patients "fill the lifestyle prescription" by becoming involved in such issues as fast-food outlets in schools, provision of safe walking/jogging/biking paths in parks, or exercise facilities in workplaces. This challenge is one that we can all take up, as members of and leaders in our communities.

Lastly, and perhaps most importantly, we need to know what really works for prehypertension. Upper and lower values for prehypertension differed in outcomes somewhat in Liszka et al's analysis, but only by $10 \mathrm{~mm} \mathrm{Hg}$ systolic or $5 \mathrm{~mm} \mathrm{Hg}$ diastolic in pressure. Are differences that small consistently measurable enough to be clinically usable in practice, or should we use the category of prehypertension as a whole? Is the entire category consistently distinguishable with time in any given patient from stage 1 hypertension or from normal pressure? What sorts of interventions that are feasible to carry out in the clinician's office make a difference in lifestyle and reduce prehypertension? What elements of care are best contributed by each member of the office team? How can we best arrange our office workflow and systems to deliver lifestyle interventions effectively? What are patients' goals? How does prehypertension fit into the care of the whole patient? How is it balanced against patients' other health care and broader life stage needs? What side effects (positive or negative) does prehypertension management have? We need answers to these questions, but we cannot rely on answers from referral centers or hypertension specialists being either effective or sustainable in our practices. Here family physicians must step forward to create the knowledge that we and our patients need, both in our academic departments and in the community as members of practice-based research networks.

To read or post commentaries in response to this article, see it online at http://www.annfammed.org/cgi/content/full/3/4/292.

Key words: Hypertension; cardiovascular diseases; treatment outcome; family practice

Submitted May 30, 2005; submitted, accepted June 2, 2005.

\section{References}

1. Liszka HA, Mainous AG, King DE, Everett CJ, Egan BM. Prehypertension and cardiovascular morbidity. Ann Fam Med. 2005;3:294-299.

2. Chobanian AV, Bakris GL, Black HR, et al. The seventh report of the Joint National Committee on Prevention, Detection, Evaluation, and Treatment of High Blood Pressure: the JNC 7 report. JAMA. 2003;289:2560-2572.

3. Russell LB, Valiyeva E, Carson JL. Effects of prehypertension on admissions and deaths: a simulation. Arch Intern Med. 2004; 164:2119-2124.

4. Tierney WM, Brunt M, Kesterson J, et al. Quantifying risk of adverse clinical events with one set of vital signs among primary care patients with hypertension. Ann Fam Med. 2004;2:209-217.

5. Phillips LS, Branch WT, Cook CB, et al. Clinical inertia. Ann Intern Med. 2001;135:825-834. 